\title{
Who can eat information? Examining the effectiveness of seasonal climate forecasts and regional climate-risk management strategies
}

\author{
Coleen Vogel ${ }^{1, *}$, Karen O'Brien ${ }^{2}$ \\ ${ }^{1}$ School of Geography, Archaeology \& Environmental Science, University of the Witwatersrand, Private Bag 3, \\ 2050 Johannesburg, South Africa \\ ${ }^{2}$ Department of Sociology and Human Geography, University of Oslo, PO Box 1096, Blindern, 0317 Oslo, Norway
}

\begin{abstract}
Southern Africa is a region facing multiple stressors, including chronic, recurrent food insecurity and persistent threats of famine. Climate information, including seasonal climate forecasts, has been heralded as a promising tool for early-warning systems and agricultural risk management in southern Africa. Nevertheless, there is concern that climate information, for example climate forecasts, are not realizing their potential value in the region. The present study considers the actual and potential roles played by climate information in reducing food insecurity in southern Africa from 2 perspectives. The first relates to improved understanding of the contextual environment in which end users operate and use information. Users, including farmers, usually operate in an environment of considerable uncertainty, reacting to and coping with multiple stressors whose impacts are not always clear or predictable. The second perspective relates to improving the current design and variety of mechanisms (e.g. climate outlook forums) for the dissemination and uptake of climate information. The first relates to improved understanding of the contextual environment in which end users operate and use information. Users, including farmers, usually operate in an environment of considerable uncertainty, reacting to and coping with multiple stressors whose impacts are not always clear or predictable. The second perspective relates to improving the current design and variety of mechanisms (e.g. climate outlook forums) for the dissemination and uptake of climate information. Climate information, it is argued, used in isolation (e.g. in 'stand alone' climate outlook forums) and undertaken in a traditional, linear fashion, where information is moved from producer to user, is divorced from the broader, complex social context in which such information is embedded. This current articulation of climate information flow represents an ineffective means of dealing with climate variability and food security. Alternative modes of interaction (e.g. using existing platforms to 'piggyback' information or seeking appropriate 'boundary organisations') should be found to sustainably manage climate risks in the region.
\end{abstract}

KEY WORDS: Climate information · Food security $\cdot$ Mainstreaming climate information $\cdot$ Sustainable development

\section{INTRODUCTION}

Sub-Saharan Africa is a region of the world facing chronic, recurrent food insecurity and persistent threats of famine (Devereux 2000a, Devereux \& Maxwell 2001, SARPN 2004, Tango International 2005). This chronic situation is the product of a number of stress factors, including climate variability in the form of extended droughts and floods. In 2002/2003, an estimated 13 million people faced food shortages as a result of severe drought in southern Africa (Oxfam 2002). In July 2002, the UN issued an appeal for US\$611 million to address the crisis in Lesotho, Malawi, Swaziland, Zambia, Zimbabwe and Mozambique (SARPN 2004). A situation of below-normal rainfall during the 2002-2004 agricultural seasons aggravated conditions in many 
parts of the region. At the time of preparing and writing this paper (2005) the region was experiencing another 'food security' crisis. Emerging research also indicates that assessment of regional climatology requires more intensive study, including research on climate-model projections and associated down-scaling of climate outlooks from regional to local scales (e.g. Hulme et al. 2005). Such variability may also constrain agricultural production (e.g. Tadross et al. 2005) and may compound existing stresses in the region. With growing concerns regarding climate change and variability in the region coupled to the heightening food crisis, there is a clear need for better-informed user and producer groups, concerned with a number of issues. With this as the backdrop, we examine the role and value of current climate information systems, the overall institutional design of such information systems and the factors enhancing or constraining the sustained longevity of such efforts.

Climate-related shocks are important triggers that severely impact on household economies, often aggravating and accentuating other conditions and stress factors (e.g. aggravated disease burdens including HIV/AIDS, and insecure livelihoods) (Mirza 2003, SARPN 2004, Tango International 2005). Managing climate variability in southern Africa has therefore become far more complex than merely dealing with extreme drought and flood events (SARPN 2004, Tango International 2005). The role that climate plays, together with other stressors in the region, is now entering the arena of development action, requiring attention not only from climate scientists but also from others, including governments and development practitioners. A number of agencies and actors, including the New Partnership for Africa's Development (NEPAD), the Southern Africa Development Community (SADC), government departments (e.g. Departments of Agriculture), disaster management agencies and a variety of non-government organisations, including humanitarian agencies (e.g. Oxfam, Care), are being drawn together and compelled to form various consortia to ensure economic growth in the face of climate stress (e.g. Benson \& Clay 1998), protect livelihoods in the region (e.g. Mock 2005) and enable progress towards the Millennium Development Goals (e.g. Dilley 2003, Mock 2005, Tango International 2005).

Climate stress, particularly in regions such as southern Africa, often exposes underlying poverty and socio-economic disparities (Sokona \& Denton 2001, Huq \& Reid 2004). This combination of factors, as we show in this paper, necessitates a sensitive reflection on the current design and architecture of climate information systems, particularly if we are to make the best sustainable use of climate information tools. A more flexible and varied communication strategy between a range of actors and users is suggested, including a re-think of the current use and overall institutional framing and design of the climate-risk management environment.

Such a shift in the linkage between climate and other causal mechanisms in a chronic and yet worsening situation of food insecurity, as persists in the SADC region, forces a re-conceptualisation and re-thinking of how climate information is produced and used. Frequently, the climate community, including producers and those involved in advocating and understanding the user end of the spectrum, resort to 'stand alone' processes (e.g. climate outlook forums) using the old fashioned, 'linear models' of information transfer (Fig. 1) that require flows of information between producers of information to end users but often through structures that are either currently weak operationally in some areas (e.g. extension agents) or via structures that are designed for limited dialogue and interaction on a semi-permanent basis (e.g. climate forums meeting once or twice a year): 'In the old model, the research community identifies operational needs and delivers the fruits of the research to the operational community, which then feeds the information to the users/decision makers' (Horsfall 2004, p. 1).

In the present study we suggest several ways of rethinking these information flows in Africa, expanding on the model provided below (Fig. 1). We also call for a variety of possible 'collaborative models' that can enable climate information to be coupled to other development and management tasks, particularly where resources may be strained and where development needs may be provided for by existing platforms, which could be utilised for 'permanent' engagement

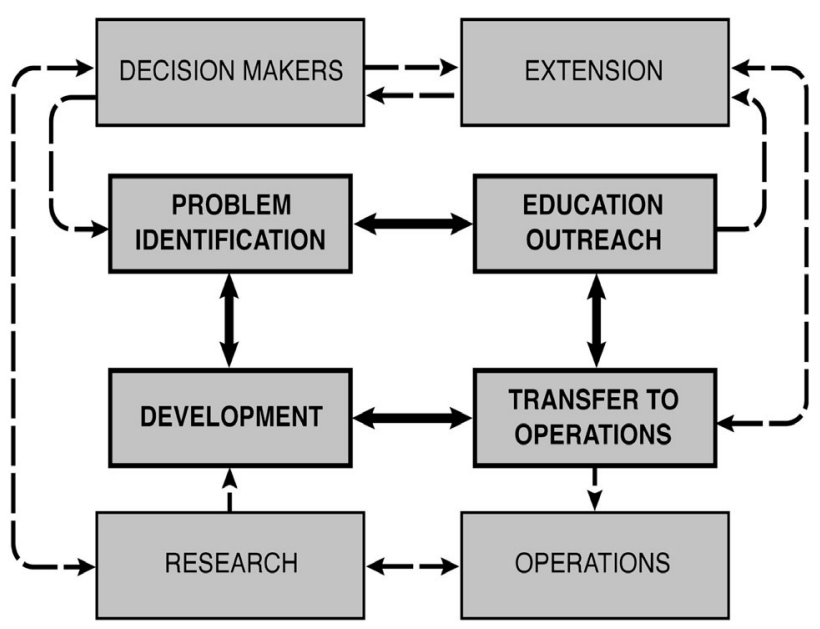

Fig. 1. Model showing possible pathways of climate information flows. These pathways are varied, and many are not fully understood (only some are indicated in the figure). Adapted from the NOAA Climate Transition Program (NCTP) (after Horsfall \& Hill 2004) 
around climate information (existing disaster management committees, NGOs, humanitarian and government groups such as the Vulnerability Assessment Committees [VACs] currently operational in the region, farmer groups, water sector managers etc.). An important dimension of this approach is the increasing commitment to integrating scientific results into effective decision support resources (Horsfall \& Hill 2004).

\section{TRADITIONAL MODEL OF CLIMATE INFORMATION TRANSFER}

In this section we examine current climate information practices in the SADC region. Climate scenario assessments and agricultural projections, based on general circulation models (GCMs), indicate that the future outlook for agriculture in the southern African region may not be promising (Fischer et al. 2002). Improved climate science, such as climate modelling and climate forecasts, is heralded as a promising tool for agricultural risk management in southern Africa, as well as in other regions (NOAA OGP 1999), particularly during periods of heightened climate stress such as drought events.

Prompted by the possibility of a strong El Niño event in 1997-1998, a number of actors involved in climate information production and use were brought together in a variety of climate outlook forums in Africa as well as other regions of the world (NOAA OGP 1999, Dilley 2003). These initial forums have been replicated by annual forums in the region, although sustaining the financial support and momentum during 'relatively climate normal' periods has been a problem (IRI 2001). Actors and stakeholders involved in the forums included producers and users of climate information such as national meteorological services, scientists (e.g. climatologists, meteorologists and social scientists), sectoral users of climate information (e.g. the water sector), and a range of agricultural producers (e.g. commercial and small-scale farmers). A seasonal climate forecast or climate outlook is produced for the region indicating possible rainfall conditions several months prior to the agricultural season, thus influencing agricultural production decisions and enabling tactical or logistical decisions for food distribution and aid programs (Klopper 1999, Martin et al. 2000, Glantz 2001, IRI 2001, Mason 2001, Dilley 2003).

The climate information used in the construction of the seasonal outlook is based on the scientific understanding of ENSO (El Niño-Southern Oscillation), a key causal mechanism that influences climate in many regions of the world, including southern Africa (e.g. Lindesay et al. 1986, Matarira 1990, Mason \& Jury 1997). Advances in understanding of the climate sys- tem over the past 2 decades has led to growing confidence that the seasonal outlooks generated from such work may be used to effectively manage climate risks (see Rasmusson \& Carpenter 1982, Philander 1983, 1990, Lindesay et al. 1986, Ropelewski \& Halpert 1987, Cane et al. 1994, Orlove \& Tosteson 1999, Stern \& Easterling 1999, Buizer et al. 2000, Cane 2000, Mason et al. 2000, Mason 2001, Goddard et al. 2003 among others). Such research has resulted in the increasing use and application of seasonal forecasts as tools for reducing risks to climate variability from a number of biophysical and social perspectives (Phillips \& McIntyre 2000, Phillips et al. 2001, Lemos et al. 2002, Patt \& Gwata 2002, Amissah-Arthur 2003, O'Brien \& Vogel 2003, Ziervogel \& Calder 2003).

Using scientifically credible products such as seasonal climate outlooks, various forums such as the Southern African Regional Climate Outlook Forum (SARCOF) provide a vehicle through which information is discussed and debated, agreed upon, and finally released for use. Although a reasonable effort was made by governments in the SADC region to inform organizations and various users and stakeholders about the possible rainfall expectations associated with the 1997-1998 season, the 'stand-alone' design of the climate outlook forums has frustrated longer-term, more proactive climate risk management. The channels for information flows to a variety of end users, particularly small-scale farmers, has been relatively poor and continues to be limited, patchy and unsuccessful, in many countries (e.g. Thomson 2003).

This past experience with climate information, combined with the persistent and chronic vulnerabilities to climate risks in the region, have prompted a growing concern that climate information (not limited to seasonal climate forecasts) is currently not being effectively debated, scrutinised and distributed amongst a variety of end users and stakeholders in the region. Despite the opportunities that such a tool provides, a preoccupation with dissemination, including issues related to the scale of forecast applicability, the understanding of probabilities used in the production of the forecast, credibility of the forecasts and other problems in communicating the 'forecast' message, often diverts the focus from the contextual situations in which these tools are embedded. Assessments of the SARCOF process, for example, include a focus on methods used and climate modelling 'jargon' that can prevent uptake of forecasts (e.g. Cash et al. 2003). Governments and meteorological bodies, as another example, have yet to develop effective methods of communicating probabilistic forecasts (e.g. Blench 1999). There are currently few assessments of the institutional requirements of forecast use and of the tensions between various users and the various systems of 'knowledge' and 
approaches that may have to be considered in the production and use of climate information.

There is often an implicit understanding that as the 'technical' constraints (described in the paragraph above) are removed and 'the message' is improved, forecasts will allow various end users and stakeholders (e.g. farmers amongst others) to improve their agricultural planning strategies, and thereby help them manage livelihood risks associated with climate variability. In other words, removing bottlenecks in the flow of information (Fig. 1) will ensure better use and uptake of climate information. The contextual environment in which agricultural decisions are made is, however, often not well understood in such assessments (e.g. How are forecasts scrutinised, debated, articulated and disseminated between various and multiple users? What is the role of various brokers of knowledge-for example, agricultural extension services - in the system of communication and use? Do they and can they provide a way of enabling farmers to gain access to forecasts?). The differences and synergies between local knowledge used to manage climate risks (in other cases referred to as indigenous knowledge) and seasonal climate forecasts (e.g. Letson et al. 2001, Broad et al. 2002, Patt \& Gwata 2002, Clay et al. 2003, O'Brien \& Vogel 2003) are also rarely profiled and given the critical attention that they require. Climate forecasts are thus seen as a promising but underutilized tool for enhancing food security.

Several key questions arise, including: 'What can be done to reduce risks and better prepare for climate variability in a region, such as southern Africa, affected by multiple stressors?' 'How can the flows, uptake and use of seasonal forecast information be improved so that they can be used as a potential risk management tool?' To answer these questions, 2 perspectives are considered. The first relates to the contextual environment in which end users operate and use information. This environment is not neutral and egalitarian. End users, including farmers, usually operate in an environment of considerable uncertainty, reacting to and coping with multiple stressors and risks whose impacts are not always clear or predictable. Climate is only one factor that influences production decisions; other factors, such as market liberalization and changes in production subsidies, are likely to confound any direct responses to climate, while HIV/AIDS is already undermining the ability of the region as a whole to respond to, let alone prepare for climate variability (Du Guerny 1999, Gari 2002, Leichenko \& O'Brien 2002, Drinkwater 2003, Scoones 2004). Climate information is also likely to have uneven effects, potentially exacerbating existing inequalities and potentially undermining local knowledge systems (Roncoli et al. 2001, Broad et al. 2002). The role of cli- mate information, its position in various ongoing dialogues in the region and its use in the 'development' arena therefore require the inclusion of a 'sociallyinformed perspective' in addition to the 'technocratic' approaches that often dominate.

The second and more fundamental perspective is that the way one interprets the linkages between climate, agriculture and food security intrinsically shapes the ways in which forecasts are usually 'framed', disseminated and eventually used. Food security can be viewed as being primarily a problem of access and entitlement to food, rather than one of only food supply and production (Devereux \& Maxwell 2001). Recent investigations in southern Africa of the progress and outcomes of the VACs - established in 2002 in 6 countries to examine the food crisis in the southern African region-have shown that measures of food production gaps are not effective in capturing the causes of food insecurity in the region (Tango International 2005), and that a wider, livelihoods-based perspective is required (e.g. Scoones 2004, Mock 2005, Tango International 2005). Such an understanding may require a more sensitive understanding of the needs of such users, prompting further research on the role of climate information in a wider livelihoods' context.

The process and 'vehicles' through and in which climate information is being transferred to end users in the southern African region is also limited. Agricultural extension agencies have been shown in several cases to be poor 'boundary institutions' for information brokering. Many farmers have little contact with such agents and therefore cannot depend on receiving timely information from such sources of information (e.g. Vogel 2000, Thomson 2003, Ziervogel \& Downing 2004). In reality the success stories, where forecasts and users have had the most useful interactions thus far, are characterised by a dialogue that has been set up and where the spectrum of constraints and risks that users and producers of forecasts confront are shared: 'Facilitating dialogue between users and producers of climate forecasts (the format of the fora in which users were able to interact with forecasters and to actively participate in the process) was considered to be one of the most positive aspects' (IRI 2001, p. 22).

However, such well-intentioned efforts are not enough, and a more critical and serious effort at mainstreaming climate risk information is required, particularly if it is to be enhanced as a tool for adaptation to climate variability (Huq \& Reid 2004). More serious interrogation of the research and practice implications of integrating forecasts with development activities is urgently required.

Climate information in the current design of 'early warning systems', and seasonal climate forums have been successfully used in the past, but these can 
arguably be enhanced by finding ways to better 'twin' information on climate variability with various development efforts, including serious thinking on the architecture and design of the organisational dimensions required for effective climate adaptation (e.g. the role of agricultural extension and local knowledge). Used alone, seasonal climate forecasts and other adaptive strategies for climate change may offer little benefit to many farmers, including commercial and smallerscale producers, their dependents and others in southern Africa whose livelihood strategies are centred on living with complex vulnerabilities, including changing state support, HIV/AIDS, and conflict (e.g. Vogel \& Smith 2002, Clover 2003, Holloway 2003, Ziervogel \& Downing 2004).

\section{3. 'A SQUARE PEG IN A ROUND HOLE': THE ROLE OF CLIMATE INFORMATION AND SOCIAL CONTEXTS}

The 1997-1998 rainfall season is a good case that illustrates the success of climate forums but also highlights some of the missed opportunities of effective use of climate information. By using data collected from an array of buoys in the Pacific Ocean and the various GCMs and statistical model outputs, and by incorporating recent advances in seasonal-to-interannual climate variability research, it was possible to predict the 1997-1998 El Niño event (Mason et al. 1999). This marked the first year that seasonal climate forecasts were widely disseminated in southern Africa. Unlike the ENSO event of 1982-1983, which was not predicted and had great economic consequences (Benson \& Clay 1998), the onset and related potential impacts of the 1997-1998 event were anticipated by the forecasts.

The 1997-1998 El Niño event, coupled with evergrowing concerns about potential climatic changes associated with global warming, contributed to the heightened awareness and desire to better manage climate fluctuations (Basher et al. 2001). Through regional meetings and pilot projects established around the world, the objective was to develop consensus forecasts, and to link international producers of forecasts with actual and potential users of these forecasts (Buizer et al. 2000).

In southern Africa, SARCOF was established in an effort to promote the dissemination of consistent and clear consensus forecasts to the user community, and to minimize the confusion that arises when conflicting forecasts from various sources are heard (NOAA OGP 1999). Seasonal climate forecasts used in the SARCOF forum provide probabilistic estimates of total rainfall relative to a $30 \mathrm{yr}$ period. They are different from short- term weather forecasts because they cover relatively larger regions and longer time spans. The resolution of the forecasts is rather coarse; one set of terciles (showing probabilities of below-normal, normal, and abovenormal rainfall) can correspond to a region covering several hundred square kilometers. Communicating such nuances to end users remains a challenge.

While assessments of the need, value, and uptake of forecasts in many parts of the world have been positive (e.g. Sonka et al. 1988, Katz \& Murphy 1997, IRI 2001), case studies in southern Africa illustrate that several factors frustrate the uptake and effective use of forecasts in this region (see Patt \& Gwata 2002, O'Brien \& Vogel 2003, Ziervogel \& Calder 2003). These factors, resonating with similar findings from other assessments in other regions, include the spatial and temporal scales of long-range forecasts, the timing of forecasts, and the diverse information and interpretation needs of different user groups (Changnon 1992, Stern \& Easterling 1999, Glantz 2001, Letson et al. 2001, O'Brien \& Vogel 2003).

Climate information, as a tool to reduce risks to climate vulnerability in southern Africa, has thus not been fully investigated from all dimensions. The use of climate information generated via such forums is sporadic, comprising heightened interest at the time of a crisis and around a SARCOF meeting, but with little attention being given to sustaining such processes once a forum is over, even though mid-season corrections are issued. There is, for example, currently a disconnection between the 'climate information enterprise' (e.g. modelling, forecast production, design, user-assessments, user needs and constraints to the uptake of forecast products) and the linkages and 'interplay' between such activities and those operating in formal institutions (e.g. Departments of Agriculture, Water Affairs, Social Welfare, etc.) as well as informal institutions (e.g. welfare organisations, church groups, NGOs, humanitarian organisations, etc.) (Fig. 2). There is also a lack of serious discussion and debate regarding the type of institutional and organisational design that may be needed to foster better dialogue on climate risk and climate information between these various stakeholders and groups (Fig. 2b). This problem is not unique to the region and has been observed in other parts of Africa and the wider world. Lusenso et al. (2003) agree with findings of Glantz (1996), Broad (2000) and Mahmoud \& Little (2000) that the focus of efforts to mitigate climate-related risk should be shifted away from the improvement of forecast skill or dissemination. Instead, greater attention needs to be given to the infrastructural and institutional advances necessary to facilitate the use of forecast information within a range of contexts, e.g. rural livelihood strategies (Lusenso et al. 2003). 
(a)

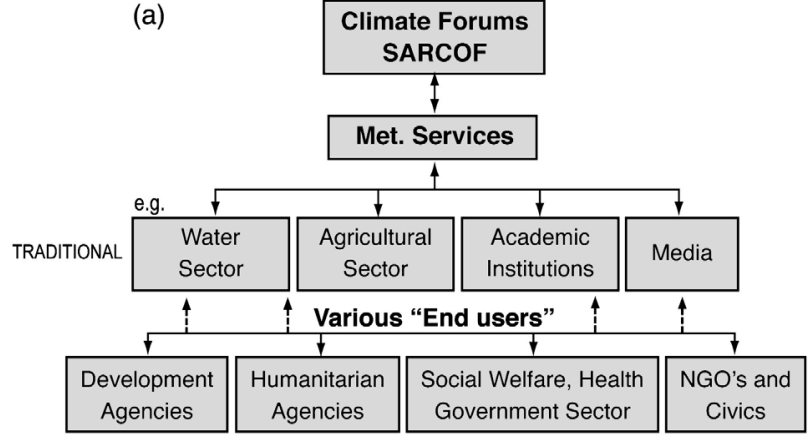

(b)

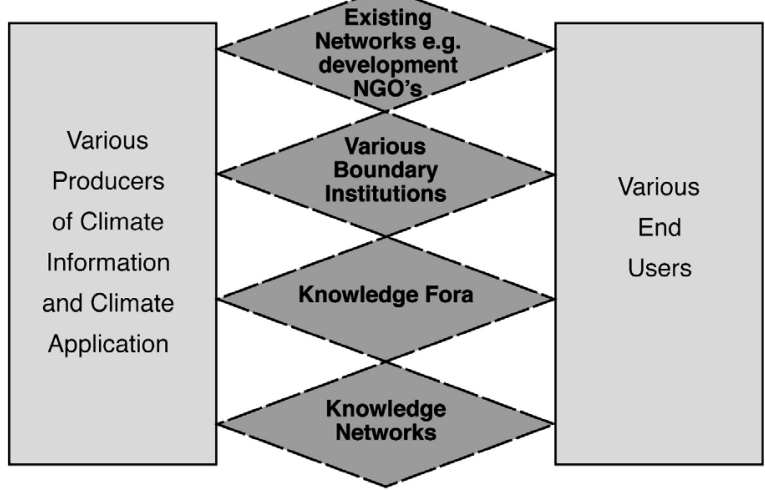

Fig. 2. Examples of climate information flows and organizational 'modes' that may be conceptualised. (a) Current climate information pathways in southern Africa. Only limited engagement occurs with organisations not 'traditionally' perceived to be users of climate information. (b) A suggested alternative model of climate information and user interaction

\section{MISSING DIMENSIONS AND CONSIDERATIONS IN CLIMATE INFORMATION SYSTEMS}

Several studies (e.g. Nelson \& Finan 2000, Broad \& Agrawala 2001, Roncoli et al. 2001, O'Brien \& Vogel 2003, Tarhule \& Lamb 2003) that scrutinize climate information uptake and use are trying to advance the central (and yet currently neglected) issues that were first raised by Glantz (1977). This early work called for a more critical evaluation of forecast use including the role and value of forecasts. More recent case studies confirm earlier concerns by showing that information dissemination and communication is not a neutral process, and that forecasts alone are not necessarily empowering, since they often overlook a number of complex interactions and processes occurring at local levels, including the use of traditional knowledge (Eakin 1999). Pulwarty et al. (2004, p. 84), for example, show that in spite of potential benefits, '...'knowledgebased' interventions can and do simplify complex situations and strengthen existing assumptions and myths about the 'powerlessness' of impacted people'.
The ability to cope and adapt and the adaptation environment in which end users operate are also fundamental issues to understand. As we have suggested already, responding to a varying climate is often constrained, not only by varying rainfall but also by other more pressing factors, including, in the case of smallscale farmers, the ability to gain access to resources that would assist them in their agricultural activities (e.g. land, labor, fertilizers and credit). There is an accumulating body of evidence showing that the use of forecasts among small-scale or communal farmers in rural areas is constrained by the limited production alternatives available upon relatively short notice, and that forecast use must be understood within the context of local livelihoods and the wider institutional environment in which forecasts are currently embedded (Eakin 1999, 2000, Nelson \& Finan 2000, O'Brien et al. 2000, Vogel 2000, Roncoli et al. 2001, Lemos et al. 2002, Tarhule \& Lamb 2003). For example, commercial and agricultural banks may foreclose on credit available to farmers on the basis of hearing a forecast for a potentially negative season. Can an advisory facility or 'dialogue' in existing agricultural structures be utilized to improve the decision-making environment in such cases?

Designing an effective climate information system also requires agreed-upon protocols related to the role and functions of meteorologists in producing forecasts, the role of intermediaries who translate the 'message' and the role of possible endorsers of the message, e.g. policy makers. Whether through radio, farmers' unions or extension services, information networks that include flows both from the center outwards, and from the grass-roots level upwards, need to be fully considered (see Moser \& Dilling 2004). Many of the existing channels for information dissemination are imperfect.

Dissemination alone, however, does not determine who receives the forecasts. Access to climate information is also determined by the internal dynamics and 'politics' within organizations such as government ministries or even households. Blench \& Marriage (1998), argue that the fields of climate forecasts (and the climate change enterprise more broadly) are 'metamorphosing from the technical to the socio-political.' They and others (e.g. Lemos et al. 2002) suggest that the consequences of climate variability must be decoded as much for their political significance as for their predictive element. Indeed, Broad et al. (2002) show that, rather than representing neutral information, the 1997-1998 forecasts in Peru carried political messages regarding expectations for the upcoming season (see also Pfaff et al. 1999).

Several case studies also suggest that some users have greater access to forecasts than others, and that village politics, ethnicity, and gender influence this 
access (Roncoli et al. 2001, Archer 2003). The choice of dissemination networks by forecast producers and government bodies also leads to the intentional or unintentional exclusion of some groups from receiving the information, creating 'insider' and 'outsider' user groups. Women, who play an important role in agriculture in southern Africa, for example, have not been specifically included to receive climate forecasts, nor has the use of forecasts by women been widely or extensively studied (see Archer 2003). Recognizing that access to forecasts is unequal is therefore a prerequisite for understanding and improving user responses. Is climate information needed? What other information may also be required to improve local livelihoods in the face of climate stress? Which local level forums and networks are the most appropriate and most suitable for beginning a climate information dialogue and information sharing process?

A key factor to consider that emerges is the overall degree of fit and design of the climate information enterprise or institution (Young \& Underdal 1997), as well as interactions between the current design and focus of forecasts and the environment in which endusers operate (Scoones 2004). Blench (2003), for example, shows that farmers' management of risk is also not a simple, linear process. Farmers make use of various agricultural strategies that are required for differing situations between seasons (e.g. normal, above-normal and below-normal periods) as well as varying conditions within seasons. Farmers' decisions and strategies are therefore seldom single, 'one-off' events, and decisions and strategies may often be reviewed throughout the season depending on a number of factors, including a range of diversification options and strategies (Eakin 2000, Ellis 2000, Francis 2000, Vogel 2000, Roncoli et al. 2001, Broad et al. 2002, Lemos et al. 2002, Amissah-Arthur 2003, Archer 2003, Ziervogel \& Calder 2003). In semi-arid areas, for example, farmers' strategies are strongly tied to a dynamic relationship with a number of factors (rainfall, crop mixtures and varieties, soil conditions, and management of soils through the period of precipitation) that tend to be strongly tied to micro-variations in climate. Assuming, therefore, that a 'one-off' forecast at the outset of a season (with a mid-season correction as currently adopted in many climate forums) may not be the most appropriate mode for optimising the production, use and uptake of climate information, alternative forums may enable a more flexible design in which climate information can be continuously accessed and debated. Livelihoods and the possible impacts of climate variability within specific contexts, therefore, need to be better understood.

There is, for example, currently little discussion between climate outlook forums and bodies concerned with the assessment of vulnerability to food insecurity in the region (e.g. VACS). Within the practice community (e.g. VACs), and the literature concerned with food security and sustainable livelihoods, vulnerability is defined as 'a high degree of exposure to risk, shocks, and stress; and proneness to food insecurity' (Ellis 2000, p. 62). Climate variability is considered a source of both shocks and stresses, depending on the nature of the impacts. Floods, for example, can be considered shocks because they have an immediate effect on food security. Droughts, in contrast, may be considered a stress if they occur over several years and thus have a cumulative effect on food security (de Haan 2000). It is often the case that vulnerability to short-term shocks is a result of poverty induced by long-term stresses (Moorehead \& Wolmer 2001). One of the implications of this research is that it is not the actual risk (i.e. climate variability) that creates negative outcomes, but the social, economic and political relations that influence the ability to cope and adapt to variable and uncertain climate conditions. What may be required then is the twinning of information such as climate information and advisories as much as possible with the coping and adaptive strategies and decisionmaking environment in which seasonal forecast recipients operate (Amissah-Arthur 2003).

Despite the variety of gaps that exist in the climate information and development arena in southern Africa, work at the local level is showing some progress, particularly on the use and uptake by smaller-scale producers (Patt \& Gwata 2002, Ziervogel $\&$ Calder 2003) as well as ongoing efforts to understand the needs of other end users (e.g. government sectors, water users etc). An example of recent fruitful efforts at enhancing current climate information research is the use of climate outlooks and the examination of multiagent modeling and food security (e.g. Bharwani et al. 2005). However, such efforts are often left to circulate amongst academics, with only limited feedback reaching local forums and with few avenues available for such approaches to be debated in wider forums (such as the Food Insecurity and Vulnerability Information and Mapping System [FIVIMS] in South Africa), or in a more sustainable manner. Illustrative examples of such cases are Vogel \& Smith (2002), O'Brien \& Vogel (2003), Ziervogel \& Downing (2004), Ziervogel et al. (2005). As is argued in this paper, the missing link to effective uptake and use of forecasts is often the lack of understanding between users and producers of forecasts and the lack of appropriate networks or institutional frames needed for the sustained use of forecasts.

We believe that while the current preoccupation with technical issues surrounding production and dissemination of forecasts is necessary, it fails to consider 
the wide array of themes and issues we have described. There is an urgent need to improve and deepen the discourse surrounding climate information, including the role of forecasts, particularly if they are to be considered as a possible tool for heightened resilience to periods of climate stress. It is not sufficient to merely discuss the role of the media or improved translation of the message. In particular, the debates around forecasts and their potential use as a tool to enhance food production cannot be developed without extending the debate to a broader consideration of issues of vulnerability, food security and the social contexts in which environmental change occurs. Questions and concerns-regarding, for example, which organisations are involved in such efforts, whether there are 'spaces' and networks for engagement with such concerned practitioners, and how these interactions may be facilitated (see Fig. 2b) — will require a different framing of the role and current operation of forecasts, and of the institutional design needed for sustainable engagement between producers and end users of climate information (Fig. 2).

\section{FROM KNOWLEDGE TO ACTION: MAKING FORECASTS USEFUL}

Despite numerous scientific, technological and humanitarian efforts to address the issues of climate risk, food insecurity remains a critical concern in southern Africa. Climate information could be a useful information tool that could be factored into interventions, particularly if the region is likely to experience heightened climate stress.

Vulnerability to climate variability in southern Africa needs to be understood in the wider context of institutional response to drought. In the case of West Africa, survey results revealed that the communication with end users is handicapped by poor utilization of drought research information by intermediary organizations (Tarhule \& Lamb 2003). In a recent assessment of forecasts information flow in the Limpopo Province, South Africa, the over-burdening of the climate information system in government, characterized by too many links in the communication chain, has been found to result in delays in effective climate risk management and effective early warning (S. Mpandeli pers. comm.). Understanding the institutional issues and dynamics surrounding the most appropriate fit of forecasts within institutions, and the scale of their use (local and/or national/regional), is a fundamental prerequisite to realizing the potential value of seasonal climate forecasts (Orlove \& Tosteson 1999). This, in turn, will require a better understanding of the linkages between producers of climate information and applica- tions and various end users, which occur through development NGOs, boundary organisations, knowledge forums and knowledge networks (Fig. 2b). Some detailed research on these key themes with respect to forecasts has been undertaken (e.g. Cash 2000). Orlove \& Tosteson (1999) analyse the changing role of institutions in Australia, Brazil, Ethiopia, Peru and Zimbabwe, as purveyors of climate information. Institutional design and configuration can either enhance or constrain climate forecast information flow and uptake.

Bringing the 'science' and 'practice' communities closer together (e.g. climate science and user interface) is not a simple process but there are some 'prototype' examples from other parts of the world that could be further investigated for possible consideration in southern Africa. For example, in the Climate Risk Management (CRM) team of the Asian Disaster Preparedness Centre (ADPC), several multi-disciplinary, institutional mechanisms are being set up at a variety of scales (e.g. national, sub-national and community levels), ensuring the sustainable and long-term generation, translation, communication and overall use of climate information. The program includes methods of communicating probabilistic information to users. Of greater interest, however, is that efforts are also being made to 'mainstream' this information into current institutional systems and government structures. Local governments, seeking the added value of climate forecasts in climate risk management, have integrated climate forecast application as a priority of their development plans. In Dumangas, Iloilo, in the Philippines, for example, a municipal ordinance provides municipal funds to support climate forecast application on a continuous basis (ADPC 2005). Such actions have not required a major, fundamental re-configuration of local government institutions, but rather a rethinking of the problem at hand and a proactive approach to climate risk management (Fig. 2). Rather than abandoning a climate outlook forum, such interaction can be coupled with either a range of existing institutional mechanisms (e.g. existing development or disaster risk reduction forums) or interaction can be generated at national, sub-national and community levels (see ADPC 2005, p. 4).

Other cases where various boundary organizations or intermediaries (Fig. 2b) are seeking to engage with producers and users of forecasts can be found (e.g. Pacific Northwest Climate Impacts Group, CIG; and in the earlier work of Broad et al. 2002). The CIG contributes actively to decision-support by including advisories (for planning purposes) on, for example, the role of future climate impacts and future water supply (regional integrated sciences and assessments, www. climate.noaa.gov/cpo_pa/risa). In other cases, several 
workshops have been arranged to assess the requirements and solve the problems that can arise when one tries to include various institutional mechanisms in forecast production and uptake (e.g. Cash \& Buizer 2004).

A detailed examination of the possible role of intermediaries and institutional design, as highlighted in the cases above, is markedly absent in the southern African region (e.g. linking climate information into development and disaster management plans on an ongoing basis). Current available decision-support systems and institutional architecture (e.g. agricultural extension) for climate risk management are fraught with problems. Agricultural extension is weakening in many parts of southern Africa (Ziervogel \& Downing 2004). Despite the ailing status of agricultural extension in many African contexts, traditional agricultural extension and para-extension (using a range of participatory approaches and a variety of other agents who may act as agricultural information brokers) may still be useful as a means of disseminating climate information and may provide insights into better climate risk management. In this paper, therefore, we are not calling for a revolution, but rather a more careful analysis of the design and overall function of current nodes in the climate information producer-user chain in southern Africa. However, understanding the functioning of such agents and other boundary organizations is critical, and much more attention needs to be given to how such organizations mediate between scientists and decision makers, how credibility and accountability is ensured in the process, and how information is mediated across various levels (Cash 2001).

\section{CONCLUSIONS}

This paper calls for a more rigorous assessment and deeper critique of the production, dissemination and uptake of seasonal forecasts. The discourse on climate information and forecasts, moreover, needs to be broadened to include the dynamic context within which forecasts are received. People cannot eat information-they can only use it to help manage their risks and adjust their livelihood activities to respond to climate stresses and shocks that come amidst a wide range of other stresses and shocks (Buchanan-Smith et al. 1994). The flexibility (or inflexibility) to respond to climate forecasts is thus dynamically determined by policies, institutional designs, processes related to globalisation and various interventions occurring at different scales and in varying contexts.

Is there a future for forecasts and other climate information in southern Africa? Inter- and intra-annual variability of rainfall may be considered the key climatic elements that determine the success of agriculture, particularly in the semi-arid tropical regions of the world (Sivakumar 1998). In southern Africa, the availability of long-term, probability-based forecasts, as a form of climate information, has important implications for various socio-economic issues including agricultural production and improved food security in the region. Forecasts can also provide potentially valuable input into famine early warning systems, and may contribute to a more timely distribution of emergency food relief (Betsill et al. 1997, Dilley 2003). Responses to present-day climate variability also form the cornerstone for adapting to future climate changes (Downing et al. 1997, Burton et al. 2002).

When anticipating potential changes in climate (e.g. possible changes in the frequency and/or magnitude of extreme events and other changes in the pattern of climate and weather systems), there is a need for improved seasonal forecasts. Of equal importance, however, is the creation of appropriate institutional 'spaces' for effective dialogues between users and producers of climate information. Rather than simply focusing all efforts on better forecasts, one should also be finding ways of linking forecasts to other development priorities (Buchanan-Smith \& Maxwell 1994). The introduction of seasonal forecasts or discussions of climate (including scenarios, outlooks, uncertainty of 'climate change science') - not only at stakeholder seasonal forecast forums but also at agricultural and land-use planning user meetings (including water, health, housing, and disaster management forums); for example, farmers' meetings and workshops-may open a dialogue that could better enhance adaptive capacities to climate variability and change.

Finally, within the growing literature on climate forecasts, there is a tendency to identify and publicize the success stories, while the failures are seldom reflected upon, and often dismissed as 'growing pains.' However, the failures of forecasts to affect livelihood strategies can offer valuable insights into the possibilities and limitations of climate forecasts. There is a need for researchers to reflect on these failures and widen the current debates surrounding the potential use of climate information. Some of the questions that need to be addressed in future discussions of climate information (e.g. forecasts) and food security in the region could include: (1) What are the users' needs, concerns and priorities? How can these be better matched to climate information including seasonal forecasts? (2) What 'user spaces' would be required and could be created for such sustained dialogues and interactions to occur? (3) In what ways can current institutions (that are related to or require climate information) inject climate information into regional and local discussions on the design of food security interventions? And finally, (4) how can such insights be used to better 
frame current government policy (and policy at other levels) relating to climate, disaster risk and development?

The anticipated return of El Niño and the possible occurrence of other climate stresses that are likely to heighten existing stresses in the southern African region necessitate the use of climate information (including climate forecasting) not only through emergency response mechanisms, but also in longer-term risk reduction and mitigation. Despite the need for greater certainty, including an improved understanding of the climate system and better forecast models, there is a point at which one should be able to use some of the derived outputs from such activities and begin to make use of climate forecasts as potential tools to enhance adaptive capacity to climatic change and other changes:

'The balance between the need for more evidence, on the one hand, and making more effective use of existing knowledge, on the other hand, is not always clear. ....the priority is not more evidence....instead....making better use of existing understanding' $\quad$ (SARPN 2004, p. 63)

To have an impact on food security in southern Africa, climate information and seasonal climate forecasts need to be placed within a much wider context that includes not only the improvements of the product (e.g. forecasts) but also efforts to better understand the needs and demands of society to better manage climate risks. If development planning, including food security planning, is to be successful, then this may require new integrated planning approaches, different considerations with regard to the institutionalization of forecasts (demand assessment, production and dissemination) and new methodologies for promoting the perception of concepts such as food security as processes rather than end products. If the emphasis continues to focus only on the production of climate information, divorced from the development needs of a region, and does not pay serious attention to the holistic implementation required to avert crisis and chronic problems, then adverse situations will persist despite wellmeaning efforts:

'Better information makes famines easier to predict; but better institutions are needed before famines become easier to prevent'

(emphasis added, Devereux 2000b, p. 25)

Acknowledgements. This paper is the result of a long struggle to better understand food security and the role that climate information could play in the southern African region. It is also the result of very wide consultations with many organizations, government departments and academics involved in mainstreaming forecasts to increase adaptive capacity to climate risk in the southern African region. It is based in part on a recent book entitled 'Coping with climate variability: the use of seasonal climate forecasts in Southern Africa', by the authors of this paper. The title and overall idea was inspired by a paper written by Buchanan-Smith et al. (1994). Those authors argued over 10 years ago that information tends to play only a peripheral role in the process of famine response, and that constraints to the response side of the equation must be addressed to realize the benefits of early warning systems.

\section{LITERATURE CITED}

ADPC (Asian Disaster Preparedness Centre ) (2005) Climate risk management. Asian Disaster Management News, July-September issue. ADPC, Pathumthani. Available at: www.adpc.net/irc06/Newsletter/2005/7-9/03.pdf

Amissah-Arthur A (2003) Targeting climate forecasts for agricultural applications in sub-Saharan Africa: situating farmers in user space. Clim Change 58:73-92

Archer ERM (2003) Identifying underserved end-user groups in the provision of climate information. Bull Am Meteorol Soc 84:1525-1532

Basher R, Clark C, Dilley M, Harrison M (eds) (2001) Coping with climate: a way forward. A multistakeholder review of Regional Climate Outlook Forums concluded at an international workshop, Report IRI-CW/01/2. International Research Institute for Climate Prediction, Palisades, NY. Available at: http://iri.columbia.edu/outreach/publication/ irireport/PretoriaSumRpt2.pdf

Benson C, Clay E (1998) The impact of drought on subSaharan African economies: a preliminary examination, Tech pap 401. The World Bank, Washington, DC

Betsill MM, Glantz MH, Crandall K (1997) Preparing for El Niño: what role for forecasts? Environment 39(10):6-28

Bharwani S, Bithell M, Downing TE, New M, Washington R, Ziervogel G (2005) Multi-agent modeling of climate outlooks and food security on a community garden scheme in Limpopo, South Africa. Phil Trans R Soc 360:2183-2194

Blench R (1999) Seasonal climate forecasting: Who can use it and how should it be disseminated? Nat Resour Perspect 47:1-8. Overseas Development Institute, London. Available at: www.odi.org.uk/nrp/47.html

Blench R (2003) Forecasts and farmers: exploring the limitations. In: O'Brien K, Vogel C (eds) Coping with climate variability: the use of seasonal climate forecasts in Southern Africa. Ashgate, Aldershot, p 59-71

Blench R, Marriage Z (1998) Climatic uncertainty and natural resource policy: What should the role of government be? Nat Resour Perspect 31. Overseas Development Institute, London. Available at: www.odi.org.uk/nrp/31.html

Broad K (2000) El Niño and the anthropological opportunity. Pract Anthropol 22:20-23

Broad K, Agrawala S (2001) The Ethiopia food crisis: uses and limits of climate forecasts. Science 289:1693-1694

Broad K, Pfaff A, Glantz M (2002) Effective and equitable dissemination of seasonal-to-interannual climate forecasts: policy implications from the Peruvian Fishery during El Niño 1997-98. Clim Change 54:415-438

Buchanan-Smith M, Maxwell S (1994) Linking relief and development: an introduction and overview. Inst Dev Stud Bull 25:2-16

Buchanan-Smith M, Davies S, Petty C (1994) Food security: let them eat information. Inst Dev Stud Bull 25(2):69-80

Buizer J, Foster J, Lund D (2000) Global impacts and regional actions: preparing for the 1997-98 El Niño. Bull Am Meteorol Soc 81:2121-2139

Burton I, Huq S, Lim B, Pilifosova O, Schipper EL (2002) From impacts assessment to adaptation priorities: the shaping of adaptation policy. Clim Policy 2:145-159 
Cane M (2000) Understanding and predicting the world's climate system. In: Hammer GO, Nicholls N, Mitchell C (eds) Applications of seasonal climate forecasting in agricultural and natural ecosystems, the Australian experience. Kluwer Academic Publishers, Dordrecht, p 29-50

Cane MA, Eshel G, Buckland RW (1994) Forecasting Zimbabwean maize yield using eastern equatorial Pacific sea temperature. Nature 370:204-205

Cash D (2000) Distributed assessment systems: an emerging paradigm of research, assessment and decision making for environmental change. Global Environ Change 10: $109-120$

Cash D (2001) 'In order to aid in diffusing useful and practical information': Agricultural extension and boundary organizations. Sci Technol Hum Values 26:431-453

Cash D, Buizer J (2004) Knowledge-action systems for seasonal to interannual climate forecasting. Report to the roundtable on Science and Technology for Sustainability, Policy and Global Affairs. The National Academies Press, Washington, DC

Cash D, Borck JC, Patt AG (2003) Countering the loadingdock approach to science and decision making. Sci Technol Hum Values 31:465-494

Changnon SA (1992) Contents of climate predictions desired by agricultural decision makers. J Appl Meteorol 76: 711-720

Clay E, Bohn L, de Armas E, Kabambe S, Tchale H (2003) Malawi and southern Africa: climatic variability and economic performance. Disaster Risk Management Working Paper Series, No. 7. The World Bank, Washington, DC

Clover J (2003) Food security in sub-Saharan Africa. Afr Food Security Rev 12:5-15

De Haan LJ (2000) Globalization, localization and sustainable livelihood. Sociol Ruralis 40:339-363

Devereux S (2000a) Famine in the twentieth century. Working Paper, Institute of Development Studies, Sussex

Devereux S (2000b) Famine in Africa. In: Devereux S, Maxwell S (eds) Food security in sub-Saharan Africa. University of Natal Press, Pietermaritzburg, p 117-148

Devereux S, Maxwell S (eds) (2001) Food Security in subSaharan Africa. ITDG Publishing, London

Dilley M (2003) Regional responses to climate variability in southern Africa. In: O'Brien K, Vogel C (eds) Coping with climate variability: the use of seasonal climate forecasts in Southern Africa. Ashgate, Aldershot, p 35-47

Downing TE, Ringius L, Hulme M, Waughray D (1997) Adapting to climate change in Africa. Mitigation Adapt Strategies Global Change 2:19-44

Drinkwater M (2003) HIV/AIDS and agrarian change in southern Africa. Technical consultation on vulnerability in the light of an HIV/AIDS pandemic. Presentation for the United Nations Inter-Agency Co-ordination and Support Office, 9-11 September, Pretoria

Du Guerny J (1999) AIDS and agriculture in Africa: Can agricultural policy make a difference? Food Nutr Agr 25: 12-19. Available at: www.fao.org/ag/agri/publications/fna/

Eakin H (1999) Seasonal climate forecasting and the relevance of local knowledge. Phys Geogr 20:447-660

Eakin H (2000) Smallholder maize production and climatic risk: a case study from Mexico. Clim Change 45:19-36

Ellis F (2000) Rural livelihoods and diversity in developing countries. Oxford University Press, Oxford

Fischer G, Shah M, van Velthuizen H (2002) Climate change and agricultural vulnerability. International Institute for Applied Systems Analysis, Laxenburg

Francis E (2000) Making a living: changing livelihoods in rural Africa. Routledge, London
Gari JA (2002) Agrobiodiversity, food security and HIV/AIDS mitigation in Sub-Saharan Africa. Sustainable Development Department, UN Food and Agriculture Organization, Rome. Available at: www.fao.org/sd/2002/pe0104a en.htm

Glantz M (1977) The value of long-range weather forecast for the West African Sahel. Bull Am Meteorol Soc 58:150-158

Glantz MH (1996) Currents of change: El Niño's impact on climate and society. Cambridge University Press, Cambridge

Glantz M (ed) (2001) Once burned, twice shy? Lessons learned from the 1997-98 El Niño. The United Nations University, Tokyo

Goddard L, Barnston AG, Mason SJ (2003) Evaluation of the IRI's 'Net Assessment' seasonal climate forecasts 1997-2001. Bull Am Meteorol Soc 84:1761-1781

Holloway A (2003) Disaster risk reduction in southern Africa: hot rhetoric - cold reality. Afr Security Rev 12:29-38

Horsfall F, Hill H (2004) NOAA Climate Transition Program, extended abstracts. American Meteorological Society, Boston

Hulme M, Doherty R, Ngara T, New M (2005) Global warming and African climate change: a reassessment. In: Low PS (ed) Climate change and Africa. Cambridge University Press, Cambridge p 29-49

Huq S, Reid H (2004) Mainstreaming adaptation in development. Inst Dev Stud Bull 35(3):15-21

IRI (International Research Institute for Climate Prediction) (2001) Coping with climate: a way forward. Report of the multi-stakeholder review of Regional Climate Outlook Forums concluded at an international workshop, 16-20 October 2000, Pretoria, South Africa. IRI Report IRICW/01/1. International Research Institute for Climate and Society, Palisades, NY

Katz R, Murphy A (1997) Economic value of weather and climate forecasts. Cambridge University Press, New York

Klopper E (1999) The use of seasonal forecasts in South Africa during the 1997/98 rainfall season. Water SA 25:311-316

Leichenko RM, O'Brien KL (2002) The dynamics of rural vulnerability to global change: the case of southern Africa. Mitigation Adapt Strategies Global Change 7:1-18

Lemos MC, Finan T, Fox R, Nelson D, Tucker J (2002) The use of seasonal climate forecasting in policy making: lessons from Northeast Brazil. Clim Change 55:479-507

Letson D, Llovet I, Podestá G, Royce F, Brescia V, Lema D, Parellada G (2001) User perspectives of climate forecasts: crop producers in Pergaminao, Argentina. Clim Res 19: 57-67

Lindesay JA, Harrison MSJ, Haffner MP (1986) The Southern Oscillation and South African rainfall. S Afr J Sci 82: 196-189

Lusenso WK, Mcpeak JG, Barrett CB, Little PD, Gebru G (2003) Assessing the value of climate forecasts information for pastoralists: evidence from southern Ethiopia and Northern Kenya. World Dev 11:1477-1494

Mahmoud H, Little PD (2000) Climatic shocks and pastoral risk management in northern Kenya. Pract Anthropol 22: $11-14$

Martin RV, Washington R, Downing T (2000) Seasonal maize forecasting for South Africa and Zimbabwe derived from an agroclimatological model. J Appl Meteorol 39:1473-1479

Mason SJ (2001) El Niño, climate change, and southern African climate. Environmetrics 12:327-345

Mason SJ, Jury MR (1997) Climatic variability and change over southern Africa: a reflection on underlying processes. Progr Phys Geogr 21:23-50

Mason SJ, Goddard L, Graham NE, Yuleava E, Sun L, Arkin P (2000) The IRI seasonal climate prediction system and 
the 1997/98 El Niño Event. Bull Am Meteorol Soc 80: $1853-1873$

Matarira CH (1990) Drought over Zimbabwe in a regional and global context. Int J Climatol 10:609-625

Mirza MMQ (2003) Climate change and extreme weather events: Can developing countries adapt? Clim Policy 3: 233-248

Mock N (2005) Vulnerability assessment methodology review, Lesotho country report. Southern African Development Community: Food, Agriculture and Natural Resources, Regional Vulnerability Assessment Committee (SADC-FANR RVAC) Gabarone, Botswana

Moorehead S, Wolmer W (2001) Food security and the environment. In: Devereux S, Maxwell T (eds) Food security in sub-Saharan Africa. University of Natal Press, Pietermaritzburg, p 93-116

Moser SC, Dilling L (2004) Making climate hot: communicating the urgency of the challenge of global climate change. Environment 46(10):32-46

Nelson DR, Finan TJ (2000) The emergence of a climate anthropology in Northeast Brazil. Pract Anthropol 22:6-10

NOAA OGP (Office of Global Programs) (1999) An experiment in the application of climate forecasts: NOAA-OGP Activities related to the 1997-98 El Niño event. Office of Global Programs, National Oceanic and Atmospheric Administration, US Department of Commerce, Washington, DC

O'Brien K, Vogel C (eds) (2003) Coping with climate variability: the use of seasonal climate forecasts in southern Africa. Ashgate, Aldershot

O'Brien K, Sygna L, Naess R, Kingamkono R, Hochobeb B (2000) Is information enough? User responses to seasonal climate forecasts in southern Africa. CICERO Report 2000-3, Centre for International Climate and Environmental Research-Oslo

Orlove B, Tosteson J (1999) The application of seasonal to interannual climate forecasts based on El Niño-Southern Oscillation (ENSO) events: lessons from Australia, Brazil, Ethiopia, Peru and Zimbabwe. Berkeley Workshop on Environmental Politics Working Paper, No. WP 99-3. Working Papers in Environmental Policy, Institute of International Studies, University of California, Berkeley

Oxfam (2002) Crisis in Southern Africa. Oxfam Briefing Report 23. Oxfam. Oxford. Available at: www.oxfam.org.uk/ what_we_do/issues/conflict_disasters/bp23_africa.htm

Patt A, Gwata C (2002) Effective seasonal forecast applications: examining constraints for subsistence farmers in Zimbabwe. Global Environ Change 12:185-195

Pfaff A, Broad K, Glantz M (1999) Who benefits from climate forecasts? Nature 397:645-646

Philander SG (1983) El Niño Southern Oscillation phenomena. Nature 302:295-301

Philander SG (1990) El Niño, La Niña and the Southern Oscillation. Academic Press, New York

Phillips J, McIntyre B (2000) ENSO and interannual rainfall variability in Uganda: implications for agricultural management. Int J Climatol 20:171-182

Phillips J, Makaudze E, Unganai L (2001) Current and potential use of climate forecasts for resource-poor farmers in Zimbabwe: impacts of El Niño and climate variability in agriculture. In: Impact of El Niño and climate variability on agriculture. Am Soc Agron Spec Publ Ser 63:87-100

Pulwarty RS, Broad K, Finan T (2004) El Niño events, fore- casts and decision-making. In: Bankoff G, Frerks G, Hilhorst $\mathrm{T}$ (eds) Mapping vulnerability: disasters, development, and people. Earthscan, London, p 83-98

Rasmusson EM, Carpenter TH (1982) Variations in tropical sea surface temperature and surface wind fields associated with the Southern Oscillation/El Niño. Mon Weather Rev 11:354-384

Roncoli C, Ingram K, Kirshen P (2001) The costs and risks of coping with drought: livelihood impacts and farmers' responses in Burkina Faso. Clim Res 19:119-132

Ropelewski CF, Halpert MS (1987) Global and regional scale precipitation patterns associated with the El Niño/Southern Oscillation (ENSO). Mon Weather Rev 115:1606-1626

SARPN (Southern African Regional Poverty Network) (2004) Scoping study towards DFIDSA's Regional Hunger and Vulnerability Programme. DFID, Pretoria

Scoones I (2004) Climate change and the challenge of nonequilibrium thinking. Inst Dev Stud Bull 35:114-119

Sivakumar MVK (1998) Climate variability and food vulnerability. Global Change Newsl (IGBP) 35:14-17

Sokona Y, Denton F (2001) Climate change impacts: Can Africa cope with the challenges? Viewp Clim Policy 1: $117-123$

Sonka ST, Changnon SA, Hofing S (1988) Assessing climate information use in agribusiness. II. Decision experiments to estimate economic value. J Clim 1:766-774

Stern PC, Easterling WE (1999) Making climate forecasts matter. Panel on the Human Dimensions of Global Change, Commission on Behavioural and Social Sciences and Education, National Research Council, National Academy Press, Washington, DC

Tadross M, Hewitson B, Usman, M T (2005) The interannual variability of the onset of the maize growing season over South Africa and Zimbabwe. J Clim 18:3356-3372

Tango International (2005) Vulnerability assessment methodology review. Tango Inernational, Tucson, AZ

Tarhule A, Lamb PJ (2003) Climate research and seasonal forecasting for West Africans: perceptions, dissemination and use. Bull Am Meteorol Soc 84:1741-1759

Thomson A (2003) National responses to seasonal forecasts in 1997. In: O'Brien K, Vogel C (eds) Coping with climate variability: the use of seasonal climate forecasts in southern Africa. Ashgate, Aldershot, p 48-58

Vogel CH (2000) Usable science: an assessment of long-term seasonal forecasts amongst farmers in rural areas of South Africa. S Afr Geogr J 82:107-116

Vogel C, Smith J (2002) The politics of scarcity: conceptualising the current food security crisis in southern Africa. S Afr J Sci 98:315-317

Young O, Underdal A (1997) Institutional dimensions of global change. IHDP Scoping Report, International Human Dimensions Programme on Global Environmental Change, Bonn

Ziervogel G, Calder R (2003) Climate variability and rural livelihoods: assessing the impact of seasonal climate forecasts. Area 35:403-417

Ziervogel G, Downing TE (2004) Stakeholder networks: improving seasonal climate forecasts. Clim Change 65: 73-101

Ziervogel G, Bithell M, Washington R, Downing T (2005) Agent-based social simulation: a method for assessing the impact of seasonal climate forecast applications among smallholder farmers. Agric Syst 83:1-26 